\title{
Commentary: When is a simple tube graft a disservice in type-A dissection?
}

\author{
Joanna Chikwe, MD
}

\footnotetext{
From the Department of Cardiovascular Surgery, Mount Sinai Medical Center, New York, NY, and Department of Surgery, The State University of New York, Stony Brook, NY.

Disclosures: Dr Chikwe has received speaker honoraria from Edwards Lifesciences.

Received for publication May 12, 2019; accepted for publication May 13, 2019; available ahead of print June 20, 2019 .

Address for reprints: Joanna Chikwe, MD, Department of Cardiovascular Surgery, Mount Sinai Medical Center, 1190 Fifth Ave, New York, NY 10029 (E-mail: Joanna.Chikwe@mountsinai.org).

J Thorac Cardiovasc Surg 2020;159:770-1

$0022-5223 / \$ 36.00$

Copyright (c) 2019 Published by Elsevier Inc. on behalf of The American Association for Thoracic Surgery

https://doi.org/10.1016/j.jtcvs.2019.05.046
}

Mennander and colleagues ${ }^{1}$ report outcomes after repair of acute type A aortic dissections in 1122 patients, including 65 patients with bicuspid valves, operated on between 2005 and 2014 at 8 Scandinavian centers participating in a retrospective clinical registry. The authors confirm the findings of previous series: , $3^{3}$ bicuspid valve patients comprised a disproportionately large number of acute typeA dissections; they presented at a substantially younger age and with larger aortic diameters than patients with trileaflet aortic valves; the aortic regurgitation phenotype was associated with higher risk; the entry tear was more commonly in the aortic root or ascending aorta and necessitated root surgery in $60 \%$ of bicuspid patients compared with only $25 \%$ of nonbicuspid patients; and despite this early mortality (17\% vs $18 \%$ ) survival at 3 years was similar.

Similar data have prompted speculation that smaller prophylactic surgery cutoffs for bicuspid aortopathy compared with trileaflet aortic valves may lead to an excess of unnecessary operations. ${ }^{2-4}$ This is a potentially important observation with important implications for practice. However, the study authors focus on emphasizing that bicuspid valves are not associated with worse outcomes after type A dissection "despite more complex surgery." This is a stretch. The bicuspid cohort is small and infrequent deaths and missing data may explain the unlikely shape of the survival curve (which rapidly becomes a horizontal line, suggesting after the early hazard phase there was no mortality in 8 years of followup). More importantly, bicuspid patients in this study were on average 7 years younger than nonbicuspid patients, and it therefore seems reasonable to ask why their early outcomes and survival were not correspondingly better than the much older nonbicuspid patients. In other words, did increased use of aortic root replacement in these patients contribute to poorer-than-expected outcomes, and was this incremental risk of root replacement an essential part of treating specific disease morphology associated with acute dissection in the setting of bicuspid aortic valves?

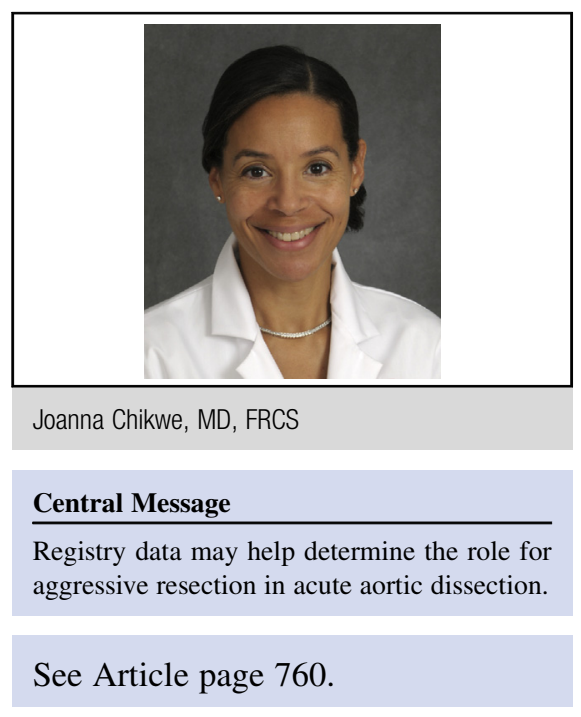

This registry could be used to explore this. The database contains information on the location of the primary tear, the extent of distal and proximal surgery, the indication for root replacement, and whether the primary tear was excluded by surgery. Surgeons reasonably assume that excluding the primary tear is desirable-if not essential-but this assumption has not been tested in a cohort of this size. Comparing the early and midterm outcomes of a Bentall root replacement versus a conservative approach; for example, an interposition graft or Wheat procedure in the 138 patients with primary tears located proximal to the sinotubular junction in this registry could provide this information. Similarly, evaluating the value of hemiarch versus total arch replacement in the 114 patients with primary tears located in the aortic arch may provide insight into the merits or drawbacks of a more conservative approach to the distal resection and repair.

There have been enough impressive reports of singledigit mortality with routine valve-sparing root replacement, and total arch (with and without elephant trunk) to raise a question: When is a simple tube graft a disservice in a patient with an acute type-A dissection? ${ }^{5}$ The answer may be in the authors' all-comers registry. Unfortunately, it is not in their analysis.

\section{References}

1. Mennander A, Olsson C, Jeppsson A, Geirsson A, Hjortdal V, Hansson EC, et al The significance of bicuspid aortic valve after surgery for acute type A aortic dissection. J Thorac Cardiovasc Surg. 2020;159:760-7.e3.

2. Rylski B, Desai ND, Bavaria JE, Vallabhajosyula P, Moser W, Pochettino A, et al. Aortic valve morphology determines the presentation and surgical 
approach to acute type A aortic dissection. Ann Thorac Surg. 2014;97: 1991-7.

3. Etz CD, von Aspen K, Hoyer A, Girbach FF, Leontyev S, Bakhtiary F, et al. Acute type A dissection: characteristics and outcomes comparing patients with bicuspid versus tricuspid valve. Eur J Cardiothorac Surg. 2015;48:142-50.
4. Della Corte A. The conundrum of aortic dissection in patients with bicuspid aortic valve: the tissue, the mechanics and the mathematics. Eur J Cardiothorac Surg. 2015;48:150-1.

5. Poon SS, Field M. Target mortality for repair of acute type A aortic dissection. J Thorac Cardiovasc Surg. 2019;157:e113-5. 